\title{
Micro-organismos Isolados de Mastite Bovina e em Leite Cru no Brasil
}

\section{Microorganisms Isolated from Bovine Mastitis and in Raw Milk in Brazil}

\author{
Patrícia Veiga de Almeida ${ }^{\mathrm{a}}$; Adelino Cunha Neto $;$ Eduardo Eustáquio de Souza Figueiredo $;$ \\ Ricardo César Tavares Carvalho*a
}

\begin{abstract}
aUniversidade de Cuiabá, Programa de Pós-Graduação Stricto Sensu em Biociência Animal. MT, Brasil. bUniversidade Federal de Mato Grosso, Programa de Pós-Graduação em Nutrição Alimentos e Metabolismos. MT, Brasil. 'Universidade Federal de Mato Grosso, Programa de Pós-Graduação Stricto Sensu em Ciência Animal. MT, Brasil. *E-mail: ricardo.ct.carvalho@kroton.com.br
\end{abstract}

\begin{abstract}
O presente artigo objetivou buscar, organizar e descrever informações sobre micro-organismos causadores de mastite e frequentemente encontrados no leite cru. Buscou-se artigos publicados de 2009 a 2019, nas bases de dados Scielo, Medline e Google acadêmico, utilizando as seguintes palavras-chaves: "mastite", "bovinos", "micro-organismos", "leite cru" e "Brasil". Após a busca, foram encontrados 46 artigos sobre mastite, dos quais 16 foram selecionados. Já sobre o leite cru, foram encontrados 82 artigos e 11 artigos foram selecionados para revisão. Os 16 artigos selecionados sobre mastite realizaram a detecção de 7 grupos, 1 famílias, 13 gêneros e 19 espécies distintas de micro-organismos caracterizados como agentes causadores de mastite bovina em diferentes regiões do Brasil. O gênero Streptococcus spp. e as espécies $S$. agalactiae, S. uberis foram descritos com maior frequência como agentes causadores de mastite, seguida pelo gênero Staphylococcus spp. e seus grupos (coagulase positiva e negativa), bem como a espécie $S$. aureus, gênero Enterococcus spp., além do gênero Corynebacterium spp. e Escherichia coli. Nos 11 artigos que abordavam sobre leite cru, Staphylococcus coagulase positiva, Staphylococcus spp. e S. aureus, além da espécie Escherichia coli foram detectados com elevada frequência. Na avaliação da mastite e do leite visualiza-se o predomínio do gênero Staphylococcus spp., Streptococcus spp, bem como outras espécies, tais como Escherichia coli, o que reforça a necessidade de monitoramento constante da saúde das glândulas dos animais, do manejo, da ordenha e do acondicionamento do leite obtido, assegurando assim, um produto saudável ao consumidor final do leite e seus derivados.
\end{abstract}

Palavras-chave: Inflamação dos Tetos de Bovinos. Mastite Bovina. Qualidade Microbiológica do Leite.

\begin{abstract}
This article aimed to search, organize and describe information about microorganisms that cause mastitis and are often found in raw milk. We searched for articles published from 2009 to 2019, in the Scielo, Medline and Google academic databases, using in this investigation in the databases the following keywords: "mastitis", "bovines", "microorganisms", "milk raw "and" Brazil ". After the search, 46 articles on mastitis were found, of which 16 were selected. As for raw milk, 82 articles were found and 11 articles were selected for review. The 16 selected articles on mastitis detected 7 groups, 1 families, 13 genera and 19 distinct species of microorganisms characterized as causative agents of bovine mastitis in different regions of Brazil. The genus Streptococcus spp. and the species S. agalactiae, S. uberis were more frequently described as agents that cause mastitis, followed by the genus Staphylococcus spp. and its groups (positive and negative coagulase), as well as the species S. aureus, genus Enterococcus spp., in addition to the genus Corynebacterium spp. and Escherichia coli. In the 11 articles that addressed raw milk, Staphylococcus coagulase positive, Staphylococcus spp. and S. aureus, in addition to the species Escherichia coli, were detected with high frequency. In the evaluation of mastitis and milk, the predominance of the genus Staphylococcus spp., Streptococcus spp, as well as other species, such as Escherichia coli, can be seen, which reinforces the need for constant monitoring of the health of animal glands, management, milking and conditioning the milk obtained, thus ensuring a healthy product for the final consumer of milk and milk products.
\end{abstract}

Keywords: Inflammation of Cattle Ceilings. Bovine Mastitis. Microbiological Quality of Milk.

\section{Introdução}

O leite e seus derivados são alimentos consumidos em grande escala mundialmente (BRASIL, 2019). Contudo, estes são objetos de preocupação dos produtores e processadores, por serem perecíveis, pois o leite é um meio nutritivo, facilitando o crescimento de micro-organismos de diferentes origens, afetando sua qualidade e gerando risco a saúde do consumidor (SILVA et al., 2017). Na maioria das vezes, a contaminação está associada ao consumo de leite cru ou pasteurizado de forma inadequada (CEMPÍRKOVÁ; MIKULOVÁ, 2009; SANTOS; FONSECA, 2007).
A composição do leite é homogênea, formada por glicerídeos, proteínas, lipídeos, sais minerais, vitaminas e enzimas, que permanecem em emulsão (MONARDES, 2004). Aproximadamente $85,3 \%$ do leite é formado por água, $14,7 \%$ de sólidos totais, 2,5 a 4,5\% de proteínas totais, 2,4 a 4,2\% de gordura, $3,8 \%$ de lactose e $0,8 \%$ de sais minerais e vitaminas (SGARBIERI, 2005). A proteína do leite é extremamente útil na construção de enzimas e tecidos corporais (WALDNER et al., 2007;) e o cálcio e fósforo auxiliam na estruturação dos ossos e dentes (CEMPÍRKOVÁ; MIKULOVÁ, 2009; SANTOS; FONSECA 2007).

Visando minimizar a contaminação do leite, controles 
e programas são implementados na cadeia produtiva do leite, desde o campo até a mesa do consumidor, como o processo de pasteurização lenta $\left(62{ }^{\circ} \mathrm{C}\right.$ a $65^{\circ} \mathrm{C}$ por 30 minutos aproximadamente), rápida $\left(72^{\circ} \mathrm{C}\right.$ a $75^{\circ} \mathrm{C}$ por 15 a 20 segundos) (Brasil, 2015), e a ultrarrápida $\left(130^{\circ} \mathrm{C}\right.$ a $150^{\circ} \mathrm{C}$ de 3 a 5 segundos) (BRASIL, 2017). O contr ole da qualidade do leite é uma dificuldade comum, principalmente, entre os pequenos produtores, pois afeta o desempenho econômico destas propriedades, tornando estes produtos não competitivos no mercado consumidor, e atinge assim, o sistema social e econômico do produtor rural (MUMIC et al., 2015). Um dos problemas dos produtores com o rebanho leiteiro é o reflexo do déficit de programas de controle na cadeia produtiva do leite como a mastite, que impacta tanto a qualidade, quanto a quantidade do produto (BRASIL, 2019).

A mastite bovina é uma patologia que provoca a inflamação da glândula mamária e se manifesta na forma clínica e subclínica, ocasionada principalmente por bactérias, mas também por protozoários, leveduras e fungos filamentosos. A mastite clínica se classifica em subaguda, aguda e superaguda, ou crônica e gangrenosa. Esse diagnóstico pode ser realizado observando o enrijecimento da glândula mamária, a presença de grumos e parênquima glandular no leite, além de exsudato de cor avermelhada (GUANDALIM; CHAVES, 2014).

Os agentes etiológicos dessa enfermidade são classificados em contagiosos, representados principalmente por Staphylococcus aureus, Streptococcus agalactiae, Mycoplasma spp. e Corynebacterium bovis, com transmissão cruzada de animal para animal ou de glândula para glândula durante o processo de ordenha manual ou mecânica. Já a quanto a contaminação ambiental, geralmente é observado a presença de micro-organimos como o Streptococcus bovis, $S$. uberis, S. dysgalactiae, Enterecoccus faecum e Enterococcus faecalis, além de bactérias gram-negativas: Escherichia coli, Klebsiella pneumoniae e Enterobacter aerogenes (ACOSTA et al., 2016; LANGONI et al., 2011).

O controle da mastite bovina se tornou pré-requisito básico para a remuneração do produtor de leite e a sua permanência nesta atividade. Portanto, deve haver o monitoramento dos pontos críticos de controle no sistema, em relação aos parâmetros existentes, para diagnóstico da mastite (BRASIL, 2019). Dos parâmetros se utiliza os critérios de Contagem de Células Somáticas 500.000 CS/mL e Contagem de Bactérias Totais $300.000 \mathrm{UFC} / \mathrm{mL}$, nos tanques de refrigeração individuais e/ou comunitário, devem ser implementadas para detecção de mastite no rebanho (BRASIL, 2018a).

A discussão teórica sobre a presença de mastite no rebanho leiteiro, identificando seus agentes causadores e sua frequência, inclusive em leite bovino cru, nos últimos 10 anos, por meio de uma revisão científica, contribui para compreensão deste agravo, visando a melhoria da qualidade do leite.

Sendo assim, a presente revisão objetiva caracterizar e relacionar os principais agentes etiológicos causadores de mastite bovina, além dos mais presentes no leite cru no Brasil, em artigos publicados em periódicos indexados, no período de 2009 a 2019.

\section{Desenvolvimento}

\subsection{Metodologia}

Para a obtenção dos artigos, foram adotados os seguintes critérios de busca: artigos publicados nas bases de dados Scielo, Medline e Google acadêmico, no período de 2009 a 2019, em língua portuguesa, utilizando-se dos descritores "Mastite", "bovinos", "micro-organismos", "leite cru" e "Brasil". As buscas ocorreram em dezembro de 2019. Foram então selecionados os artigos em português publicados nos últimos dez anos, com mais de um agente etiológico causador de mastite, e artigos que avaliavam o leite cru. Ao todo foram encontrados 46 artigos sobre mastite, e 82 sobre leite cru, perfazendo 128 artigos. Após a leitura dos títulos e resumos, houve a seleção os artigos sobre mastite e sobre análises de leite cru para leitura na íntegra. Foram selecionados apenas os artigos que atenderam aos critérios de seleção propostos: abordagem dos principais agentes etiológicos causadores da mastite; os mais presentes no leite cru; realizados no Brasil nos últimos 10 anos.

Do total dos 128 artigos encontrado como resultado da pesquisa, foram selecionados para a revisão, 27 artigos que atenderam os critérios adotados. Destes, 25 artigos foram publicados no Brasil e dois em países da América do Sul. No período de 2009 a 2019, e apresentaram resultados sobre mastite bovina nas diversas regiões brasileiras

\subsection{Resultados}

Nos 27 artigos selecionados nesta revisão 16 foram de estudos com mastite bovina nos quais se descrevem a detecção de 7 grupos, 1 famílias, 13 gêneros e 19 espécies distintas de micro-organismos.

Entre as descrições de somente gênero, Streptococcus spp. apresentou uma elevada ocorrência sendo relatado em $68,75 \%$ $(11 / 16)$ dos artigos, seguido pelo gênero Corynebacterium spp. $56,25 \%$ (9/16) dos artigos, outros dois gêneros pertencentes a família Micrococaceae, foram revelados em frequência discretamente elevada, Staphylococcus spp. e Micrococcus spp, com percentuais de 37,50\% (6/16) e 31,25\% $(5,16)$ dos artigos citando suas detecções, respectivamente (Quadro 1). Bacillus spp., Enterococcus spp., Klebsiella spp., Nocardia spp. e Proteus spp. são descritos em menos de $20 \%$ dos artigos selecionados (Quadro 1). Percentuais de artigos em que também se descrevem a observação de gêneros de fungos como Candida spp. e Trichosporon spp., além do protozoário Prototheca spp. como agentes causadores de mastites (Quadro1). 
Quadro 1 - Frequências de micro-organismos detectados como agente causal de mastite bovina no período de 2009 a 2019 , no Brasil

\begin{tabular}{|c|c|c|c|c|c|c|c|c|c|c|c|c|c|c|c|c|c|c|}
\hline \multirow[t]{2}{*}{$\begin{array}{c}\text { Grupo, Família, Gênero e } \\
\text { Espécie }\end{array}$} & \multicolumn{16}{|c|}{ Autor/Ano/Localização } & \multicolumn{2}{|c|}{ Total } \\
\hline & 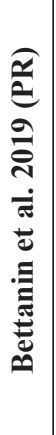 & 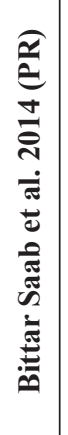 & 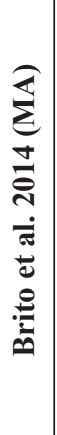 & 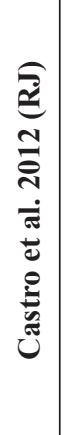 & 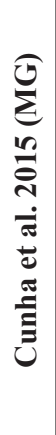 & 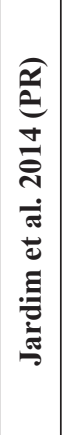 & 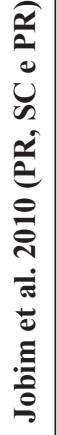 & 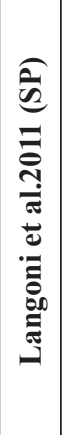 & 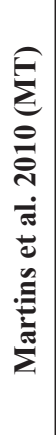 & 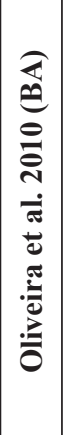 & 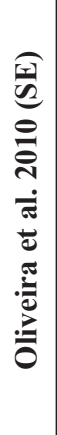 & 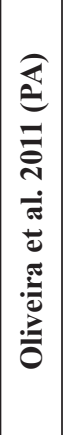 & 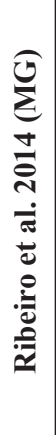 & 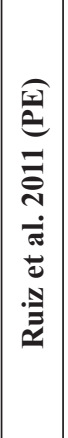 & 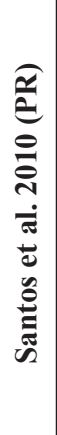 & 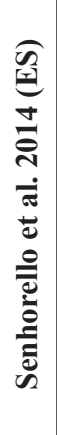 & 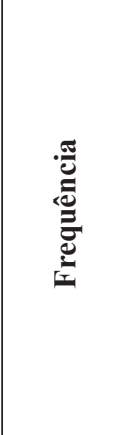 & 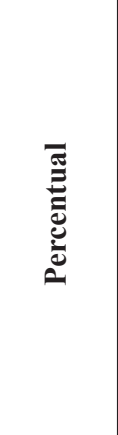 \\
\hline Staphylococcus spp. & 1 & 0 & 0 & 0 & 0 & 1 & 1 & 0 & 0 & 0 & 0 & 0 & 1 & 1 & 1 & 1 & $(06 / 16)$ & $37,50 \%$ \\
\hline Staphylococcus Coagulase (+) & 0 & 1 & 1 & 0 & 0 & 0 & 0 & 0 & 1 & 0 & 1 & 0 & 1 & 0 & 1 & 1 & $(07 / 16)$ & $43,75 \%$ \\
\hline Staphylococcus Coagulase (-) & 0 & 1 & 1 & 1 & 1 & 0 & 0 & 0 & 1 & 1 & 1 & 1 & 0 & 0 & 1 & 1 & $(10 / 16)$ & $62,50 \%$ \\
\hline Staphylococcus aureus & 1 & 0 & 1 & 1 & 1 & 1 & 0 & 1 & 1 & 1 & 1 & 1 & 1 & 0 & 1 & 1 & $(13 / 16)$ & $81,25 \%$ \\
\hline Staphylococcus intermedius & 0 & 0 & 0 & 1 & 1 & 0 & 0 & 0 & 1 & 0 & 0 & 1 & 0 & 0 & 0 & 0 & $(04 / 16)$ & $25 \%$ \\
\hline Staphylococcus epidermidis & 0 & 0 & 0 & 0 & 0 & 0 & 0 & 1 & 0 & 0 & 0 & 0 & 0 & 0 & 1 & 0 & $(02 / 16)$ & $12,50 \%$ \\
\hline Staphylococcus hyicus & 0 & 0 & 0 & 0 & 0 & 0 & 0 & 1 & 0 & 0 & 0 & 0 & 0 & 0 & 1 & 0 & $(02 / 16)$ & $12,50 \%$ \\
\hline Staphylococcus schleiferi & 0 & 0 & 0 & 1 & 0 & 0 & 0 & 0 & 0 & 0 & 0 & 0 & 0 & 0 & 0 & 0 & $(01 / 16)$ & $6,25 \%$ \\
\hline Streptococcus spp. & 0 & 1 & 1 & 1 & 1 & 0 & 1 & 0 & 1 & 1 & 0 & 0 & 1 & 1 & 1 & 1 & $(11 / 16)$ & $68,75 \%$ \\
\hline Streptococcus agalactiae & 1 & 0 & 0 & 0 & 1 & 1 & 1 & 1 & 1 & 0 & 1 & 0 & 0 & 0 & 1 & 0 & $(08 / 16)$ & $50 \%$ \\
\hline Streptococcus dysgalactiae & 1 & 0 & 0 & 0 & 1 & 1 & 0 & 1 & 1 & 0 & 0 & 1 & 0 & 0 & 0 & 0 & $(06 / 16)$ & $37,50 \%$ \\
\hline Streptococcus uberis & 1 & 0 & 0 & 0 & 1 & 1 & 0 & 1 & 1 & 0 & 0 & 1 & 0 & 0 & 0 & 0 & $(06 / 16)$ & $37,50 \%$ \\
\hline Streptococcus bovis & 0 & 0 & 0 & 0 & 0 & 0 & 1 & 1 & 0 & 0 & 0 & 0 & 0 & 0 & 0 & 0 & $(02 / 16)$ & $12,50 \%$ \\
\hline Enterococcus spp. & 1 & 0 & 0 & 0 & 0 & 0 & 0 & 0 & 0 & 0 & 0 & 0 & 0 & 0 & 0 & 0 & $(01 / 16)$ & $6,25 \%$ \\
\hline Micrococcus spp. & 1 & 0 & 0 & 0 & 1 & 1 & 0 & 0 & 1 & 0 & 0 & 0 & 0 & 1 & 0 & 0 & $(05 / 16)$ & $31,25 \%$ \\
\hline Bacilo Gram-positivo & 0 & 0 & 1 & 1 & 0 & 0 & 0 & 0 & 0 & 0 & 0 & 0 & 0 & 0 & 0 & 0 & $(01 / 16)$ & $6,25 \%$ \\
\hline Corynebacterium spp. & 1 & 1 & 1 & 0 & 0 & 1 & 0 & 0 & 1 & 1 & 1 & 1 & 0 & 1 & 0 & 0 & $(09 / 16)$ & $56,25 \%$ \\
\hline Corynebacterium bovis & 0 & 1 & 0 & 0 & 0 & 0 & 0 & 1 & 0 & 0 & 0 & 0 & 0 & 0 & 1 & 0 & $(03 / 16)$ & $18,75 \%$ \\
\hline Nocardia spp. & 1 & 0 & 0 & 0 & 0 & 0 & 0 & 1 & 1 & 0 & 0 & 0 & 0 & 0 & 0 & 0 & $(03 / 16)$ & $18,75 \%$ \\
\hline Bacillus spp. & 1 & 0 & 0 & 0 & 0 & 0 & 0 & 0 & 0 & 1 & 0 & 0 & 0 & 1 & 0 & 0 & $(03 / 16)$ & $18,75 \%$ \\
\hline Bacilo Gram-negativo & 0 & 1 & 0 & 0 & 0 & 0 & 0 & 0 & 0 & 0 & 0 & 0 & 0 & 1 & 0 & 0 & $(02 / 16)$ & $12,50 \%$ \\
\hline Pseudomonas spp. & 1 & 0 & 0 & 1 & 0 & 0 & 0 & 0 & 0 & 1 & 1 & 0 & 0 & 0 & 0 & 0 & $(04 / 16)$ & $25 \%$ \\
\hline Pseudomonas aeruginosa & 0 & 0 & 0 & 0 & 0 & 0 & 0 & 1 & 0 & 0 & 0 & 0 & 0 & 0 & 0 & 0 & $(01 / 16)$ & $6,25 \%$ \\
\hline Coliformes totais & 0 & 0 & 0 & 0 & 0 & 0 & 0 & 0 & 0 & 0 & 0 & 0 & 0 & 0 & 1 & 0 & $(01 / 16)$ & $6,25 \%$ \\
\hline Familia Enterobacteriaceae & 1 & 0 & 0 & 0 & 0 & 0 & 1 & 0 & 0 & 0 & 0 & 0 & 0 & 0 & 0 & 0 & $(02 / 16)$ & $12,50 \%$ \\
\hline Escherichia coli & 0 & 0 & 0 & 1 & 0 & 0 & 1 & 1 & 1 & 1 & 0 & 0 & 1 & 1 & 0 & 0 & $(07 / 16)$ & $43,75 \%$ \\
\hline Klebsiella spp. & 0 & 0 & 0 & 0 & 0 & 0 & 0 & 0 & 0 & 1 & 0 & 0 & 0 & 0 & 0 & 0 & $(01 / 16)$ & $6,25 \%$ \\
\hline Klebsiella pneumoniae & 0 & 0 & 0 & 0 & 0 & 0 & 0 & 1 & 0 & 0 & 0 & 0 & 0 & 0 & 0 & 0 & $(01 / 16)$ & $6,25 \%$ \\
\hline Klebsiella oxytoca & 0 & 0 & 0 & 1 & 0 & 0 & 0 & 0 & 0 & 0 & 0 & 0 & 0 & 0 & 0 & 0 & $(01 / 16)$ & $6,25 \%$ \\
\hline Proteus spp. & 0 & 0 & 0 & 0 & 1 & 0 & 0 & 0 & 0 & 1 & 0 & 0 & 0 & 0 & 0 & 0 & $(02 / 16)$ & $12,50 \%$ \\
\hline Proteus mirabilis & 0 & 0 & 0 & 1 & 0 & 0 & 0 & 0 & 0 & 0 & 0 & 0 & 0 & 0 & 0 & 0 & $(01 / 16)$ & $6,25 \%$ \\
\hline Proteus vulgaris & 0 & 0 & 0 & 0 & 0 & 0 & 0 & 0 & 1 & 0 & 0 & 0 & 0 & 0 & 0 & 0 & $(01 / 16)$ & $6,25 \%$ \\
\hline Pateurella multocida & 0 & 0 & 0 & 0 & 0 & 0 & 0 & 1 & 0 & 0 & 0 & 0 & 0 & 0 & 0 & 0 & $(01 / 16)$ & $6,25 \%$ \\
\hline Bactérias mesófilos & 0 & 0 & 0 & 0 & 0 & 0 & 0 & 0 & 0 & 0 & 0 & 0 & 1 & 0 & 0 & 0 & $(01 / 16)$ & $6,25 \%$ \\
\hline Leveduras & 0 & 0 & 1 & 0 & 1 & 0 & 0 & 0 & 0 & 0 & 1 & 0 & 0 & 0 & 1 & 0 & $(04 / 16)$ & $25 \%$ \\
\hline Candida spp. & 0 & 1 & 0 & 0 & 0 & 0 & 0 & 0 & 1 & 0 & 0 & 0 & 0 & 1 & 0 & 0 & $(03 / 16)$ & $18,75 \%$ \\
\hline Candida albicans & 1 & 1 & 0 & 0 & 0 & 0 & 0 & 0 & 0 & 0 & 0 & 0 & 0 & 0 & 0 & 0 & $(02 / 16)$ & $12,50 \%$ \\
\hline Candida kusei & 0 & 0 & 0 & 0 & 0 & 0 & 0 & 1 & 0 & 0 & 0 & 0 & 0 & 0 & 0 & 0 & $(01 / 16)$ & $6,25 \%$ \\
\hline Trichosporon spp. & 0 & 0 & 0 & 0 & 0 & 0 & 0 & 1 & 0 & 0 & 0 & 0 & 0 & 0 & 0 & 0 & $(01 / 16)$ & $6,25 \%$ \\
\hline Prototheca spp. & 1 & 0 & 0 & 0 & 0 & 0 & 0 & 0 & 0 & 0 & 0 & 0 & 0 & 0 & 0 & 0 & $(01 / 16)$ & $6,25 \%$ \\
\hline
\end{tabular}

Legenda: 0 - micro-organismo não descrito no referido estudo; 1 - micro-organismo descrito no referido estudo.

Fonte: Dados da pesquisa. 
Staphylococcus aureus foi a espécie com a detecção mais elevada, pois, é descrito em 81,25\% (13/16), dos artigos relativos a mastite bovina, selecionados. Streptococcus agalactiae com 50\% (8/16), Escherichia coli 43\% (7/126), Streptococcus dysgalactiae e $S$. uberis representado em 37,50\% (6/16), cada, nos artigos selecionados, já Staphylococcus intermedius é descrito em 25\% (4/16) dos artigos relativos a mastite. Estes percentuais mostram que os cocos Gram positivos configuram entre os mais frequentes causadores de mastite bovina no Brasil.

Quando se observa a descrição dos microrganismos somente em nível de grupo verifica-se que Staphylococcus spp., tanto coagulase positiva, quanto negativa, figuram entre os mais citados descritos em 43,75\% (7/16) e 62,50\% (10/16) dos artigos selecionados. Outros grupos de microrganismos descritos, mas, em baixos percentuais foram dos bacilos Gram positivos e negativos, coliformes totais, bactérias mesófilas e leveduras (Quadro 1).

Dentre os 27 artigos selecionados no presente estudo, 11 artigos descreveram pesquisa em leite cru de diferentes origens, tais como: tanques de resfriamento, galões, ordenhadeiras e comercio varejista (Quadro 2).

Quadro 2 - Frequências de micro-organismos detectados em leite cru no período de 2009 a 2019, no Brasil

\begin{tabular}{|c|c|c|c|c|c|c|c|c|c|c|c|c|c|}
\hline \multirow[t]{2}{*}{ Grupo, Família, Gênero e Espécie } & \multicolumn{11}{|c|}{ Autor/Ano/Localização } & \multicolumn{2}{|c|}{ Total } \\
\hline & 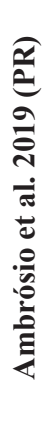 & 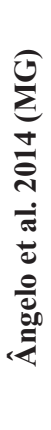 & 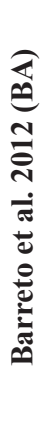 & 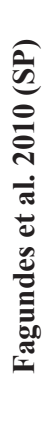 & 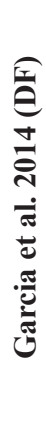 & 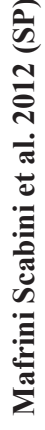 & 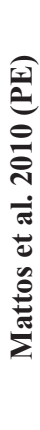 & 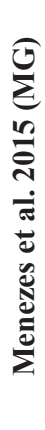 & 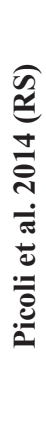 & 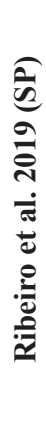 & 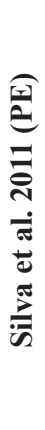 & 窇 & 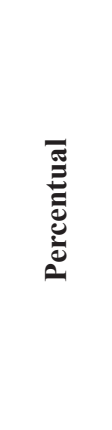 \\
\hline Bactérias Mesófilas Aeróbias & 1 & 0 & 1 & 0 & 1 & 1 & 1 & 0 & 0 & 0 & 1 & $(06 / 11)$ & $54,55 \%$ \\
\hline Bactérias Psicrotróficas & 1 & 0 & 1 & 0 & 1 & 0 & 1 & 1 & 0 & 0 & 1 & $(06 / 11)$ & $54,55 \%$ \\
\hline Staphylococcus spp. & 0 & 1 & 1 & 1 & 0 & 0 & 0 & 0 & 1 & 0 & 0 & $(04 / 11)$ & $36,36 \%$ \\
\hline Staphylococcus Coagulase Positiva & 1 & 1 & 1 & 0 & 0 & 0 & 1 & 0 & 0 & 0 & 1 & $(05 / 11)$ & $45,45 \%$ \\
\hline Staphylococcus aureus & 0 & 0 & 1 & 0 & 1 & 1 & 0 & 0 & 1 & 0 & 0 & $(04 / 11)$ & $36,36 \%$ \\
\hline Streptococcus spp. & 0 & 0 & 0 & 0 & 1 & 0 & 0 & 0 & 0 & 0 & 0 & $(01 / 11)$ & $9,09 \%$ \\
\hline Enterococcus spp. & 0 & 0 & 0 & 0 & 0 & 0 & 0 & 1 & 0 & 0 & 0 & $(01 / 11)$ & $9,09 \%$ \\
\hline Coliformes totais & 1 & 0 & 0 & 0 & 1 & 1 & 1 & 1 & 0 & 0 & 1 & $(06 / 11)$ & $54,55 \%$ \\
\hline Coliformes termotolerantes & 1 & 0 & 0 & 0 & 0 & 1 & 0 & 0 & 0 & 0 & 0 & $(02 / 11)$ & $18,18 \%$ \\
\hline Família Enterobacteriaceae & 0 & 0 & 0 & 0 & 0 & 0 & 0 & 0 & 1 & 0 & 0 & $(01 / 11)$ & $9,09 \%$ \\
\hline Escherichia coli & 0 & 0 & 0 & 0 & 1 & 1 & 1 & 0 & 0 & 1 & 1 & $(05 / 11)$ & $45,45 \%$ \\
\hline Salmonella spp. & 0 & 0 & 0 & 0 & 1 & 1 & 0 & 0 & 0 & 0 & 0 & $(02 / 11)$ & $18,18 \%$ \\
\hline
\end{tabular}

Legenda: 0 - micro-organismo não descrito no referido estudo; 1 - micro-organismo descrito no referido estudo.

Fonte: Dados da pesquisa.

Umelevado percentual de citação do gênero Staphylococcus spp. 36,36\% (4/11), do grupo Staphylococcus coagulase positiva 45,45\% (5/11), e das espécies Staphylococcus aureus $36,36 \%$ (4/11) e Escherichia coli 45,45\% (5/111), nos artigos que estudaram leite cru, mostram percentuais similares àqueles observados em estudos com mastite bovina (Quadro 2). Demonstrando uma relação entre a saúde do teto com a qualidade do leite.

Grupos de microrganismos com coliformes totais, contagem de bactérias mesófilas e psicrotróficas são utilizados como indicadores de má qualidade higiênica de obtenção de produtos alimentares (ICMSF, 2000). Os percentuais de artigos que descrevem estes grupos de microrganismos foram $54,55 \%(6 / 11)$, para os três grupos citados acima (Quadro 2).

\subsection{Discussão}

Investigações que proporcione o acompanhamento do perfil dos microrganismos patogênicos, agentes causais de mastite bovina, é imprescindível, nas diferentes regiões do Brasil. Sendo informações importantes na área de sanidade animal, e na de qualidade do leite (SANTOS et al., 2010).

O predomínio de relatos de Staphylococcus aureus e Corynebacterium spp. que são agentes causadores de mastite de origem infecciosa, e Escherichia coli de origem ambiental 
são preocupantes (ACOSTA et al., 2016; LANGONI et al., 2011). O relato dos microrganismos de origem infecciosa, indicam a ocorrência de falhas de higiene durante a ordenha, $\mathrm{e}$ alerta para o risco de animais portadores de mastites atuarem como fonte de infecção para o rebanho (MARTINS et al., 2010). A presença de Escherichia coli com agente de mastite, está relacionada a procedimentos inadequados de higiene do ambiente habitado pelo rebanho, e inadequada higienização dos tetos antes da ordenha, pois, este é um microrganismo entérico eliminado nas fezes dos mamíferos no ambiente (OLIVEIRA et al., 2010).

A elevada presença de $S$. aureus, agente causal mais prevalente nas manifestações subclínicas da mastite, indica a possibilidade de alguns animais serem portadores desta patologia, podendo contaminar outros animais do rebanho (RIBEIRO et al., 2014). A disseminação de $S$. aureus no rebanho é um fenômeno bastantes dinâmico, podendo ser impactado pelo manejo, tais como, a ordenha mecânica sistêmica, que quando bem realizada diminui ocorrências de mastite por essa espécie de microrganismo (COSTA et al., 2013).

$\mathrm{O}$ aspecto preocupante para saúde humana da ocorrência de organismo do gênero Staphylococcus spp., em mastite e no leite cru é a produção de enteroxina estafilocócica, que é termorresistente, e foi observada em 23,6\% (164) de 696 cepas de $S$. aureus isoladas leites mastítico de 140 fazendas leiteiras da Coreia (Moon et al., 2007). No Brasil, Stamford et al. (2006), observaram 17,43\% (19) de cepas de $S$. aureus produtor de enterotoxina estafilocócica entre, 109 cepas do gênero Staphylococcus spp., isoladas do leite cru. Cepas de outras espécies observadas nesta revisão, tais como, $S$ intermedius e $S$. hyicus, e dos grupos Staphylococcus coagulase positiva e negativa, que também são descritas como produtoras de enterotoxina estafilocócica por Stamford et al. (2006) no leite de animais com mastite subclínica de oito fazendas, em Garanhuns, PE.

A elevada descrição nos artigos da ocorrência de cepas das espécies Staphylococcus aureus e Streptococcus agalactiae, e do grupo Staphylococcus coagulase positiva no leite, sugere não ter havido total adesão dos produtores de leite do Brasil às técnicas higiênicas de ordenha incentivadas, no período da revisão pelas instruções normativas de $n^{\circ} 62$ de 29 de dezembro de 2011 (BRASIL, 2011), e de no 76 e 77 de 26 de dezembro de 2018 (Brasil, 2018a; Brasil 2018b). Pois, segundo Bettanin et al. (2019), a adesão as técnicas de higiene, possibilitaria a diminuição ocorrência destes microrganismos no leite (BETTANIN et al.,2019).

Segundo Zafalon et al. (2008) clima quente do verão é um fator preponderante, geralmente associado ao inadequado manejo das vacas no período seco, na elevada ocorrência de mastite causados por microrganismos pertencentes ao gênero Staphylococcus spp. Este gênero juntamente com a espécie Staphylococcus aureus foram citada com maior frequência nos relatos de mastite nesta revisão. No período dos estudos na região Sul (Santa Catarina, e Paraná), no ano de 2010, as temperaturas foram de $20^{\circ} \mathrm{C}$ a $24^{\circ} \mathrm{C}$ (JOBIM et al., 2010; SANTOS et al., 2010), no Paraná nos anos de 2019 e 2014 , temperaturas foram de $24^{\circ} \mathrm{C}$ a $26^{\circ} \mathrm{C}$, respectivamente (BERTTANIN et al., 20019; JARDIM et al., 2014). No Sudeste os anos de 2011, 2012, 2014 e 2015, nas temperaturas foram de $24{ }^{\circ} \mathrm{C}$ em São Paulo (LANGONI et al., 2011) e no Rio de Janeiro (CASTRO et al., 2012), de $26{ }^{\circ} \mathrm{C}$ no Espirito Santos (SENHORELLO et al., 2014) e Minas Gerais (CUNHA et al., 2015), no Nordeste as temperaturas foram de $26{ }^{\circ} \mathrm{C}$ em Pernambuco (RUIZ et al., 2011) e em Sergipe (OLIVEIRA et al., 2010), $28^{\circ} \mathrm{C}$ na Bahia (OLIVEIRA et al., 2010), e Norte de $30^{\circ} \mathrm{C}$ no Pará (OLIVEIRA et al., 2011).

Em todos os artigos citados acima houve a ocorrência de Staphylococcus spp. ou S. aureus, e as temperaturas descritas no período são dados divulgados pelo Instituto Nacional de Meteorologia (Inmet), órgão do Ministério da Agricultura, Pecuária e Abastecimento (Mapa), e organizado e publicados por Fioravanti (2020). Zafalon et al. (2008), observou maior percentual de ocorrência destes microrganismos em temperatura ambiental entre $20^{\circ} \mathrm{C}$ e $26^{\circ} \mathrm{C}$, as mesmas que predominaram no período dos estudos.

Contudo, os fatores que mais influenciam o aumento da ocorrência de mastite é a tecnificação do sistema de produção leite, associado ao aumento da produtividade, e consequentemente falhas no manejo de ordenha e higienização dos equipamentos (SAAB et al., 2014). De acordo com Saab et al. (2014) e Jardim et al. (2014), pode-se afirmar que há uma deficiente higienização durante a obtenção do leite, sendo em diversas propriedades leiteiras em todas as regiões do Brasil (Centro-oeste, Nordeste, Norte, Sudeste e Sul), proporcionando assim uma elevada carga microbiana e a presença de diversos micro-organismos já citados (Quadros 1 e 2).

Os procedimentos que mais contribuem para evitar a mastite é a antissepsiadas dos tetos antes e após a ordenha, pois evitam a disseminação de agentes infecciosos e aparecimento de novas infecções (BRITO et al., 2014). A água utilizada para a higienização, também pode servir de veículo carreador de micro-organismos patogênicos para úbere, sendo assim outro fator preocupante, devendo ser controlada quanto a sua pureza para ser utilizada no manejo e consumo dos animais, fator este que por muitas vezes é ignorado nas propriedades (CUNHA et al., 2015).

Medidas quanto ao correto manejo higiênico-sanitário nas propriedades, tratamento criterioso dos animais e retirada de substratos que favoreçam o desenvolvimento de parasitos, podem auxiliar os produtores no controle de parasitoses, como também de outras enfermidades no rebanho, bem como no controle de mastite bovina, favorecendo em uma melhor imunidade dos animais (CASTRO et al., 2012).

O controle da mastite requer investigação sistemática, 
que podem ser realizados por testes como California Mastitis Test (CMT), e o teste da caneca do fundo preto. O CMT é positivo pela reação do DNA de leucócitos com reagente do CMT, que começa a reagir com contagens $\geq 900.000$ células somáticas por $\mathrm{mL}$ de leite, indicativas de mastite subclínica, já teste da caneca identifica alterações como presença de grumos, consistência mais aguada do leite, além de sangue e pus, alterações observadas na mastite clínica instalada (MASSOTE et al., 2019). Tal identificação visa proporcionar o reconhecimento, a avaliação e a interpretação dos fatores epidemiológicos mais importantes, possibilitando dessa forma a aplicação de medidas de controle da infecção, com ênfase na higiene e terapia, levando em consideração as características epidemiológicas da doença (OLIVEIRA et al., 2010).

A orientação técnica realizada pelo médico veterinário pode contribuir com a redução da mastite nos rebanhos bovinos, através da identificação possíveis problemas de manejo dos animais e produção do leite, além da verificação de perfil de resistência dos micro-organismos, que é de extrema importância, podendo reduzir os gastos com medicamentos, realizar um tratamento eficaz, e consequentemente não favorecer a indução de resistência destes micro-organismos (SENHORELLO et al., 2013).

O Ministério da Agricultura, Pecuária e Abastecimento (MAPA), visando a garantia da qualidade da produção do leite estabelece regulamentos técnicos de produção, coleta e transporte (refrigerado), cuidados a serem implementados desde a ordenha até a sua unidade de beneficiamento (BRASIL, 2015; BRASIL, 2018a; 2018b). Entre estes cuidados destaca-se a coleta do leite a granel. Nesse sistema, o leite cru, armazenado em tanque de expansão a $4{ }^{\circ} \mathrm{C}$ por até 48 horas e transportado para a indústria beneficiadora em tanques isotérmicos (BRASIL, 2015; BRASIL, 2018a; 2018b). Esse processo visa reduzir o desenvolvimento da microbiota mesofílica, dentre as quais o gênero Staphylococcus spp., que se destaca como micro-organismo patogênico, potencialmente reconhecido como produtor de toxinas (RIBEIRO et al., 2019; PICOLI et al., 2014; MATTOS et al., 2010).

Entre os indicadores mais utilizados para a qualidade higiênica sanitária dos alimentos, destacam-se o grupo dos Staphylococcus coagulase positiva e coliformes, sendo os coliformes indicadores de contaminação ambiental e as vezes fecal, podendo ser um risco a presença de micro-organismos patogênicos, como a E. coli e Salmonella spp. (ÂNGELO et al., 2014). Os Staphylococcus são de grande importância, principalmente as coagulase-positiva, pois podem produzir enterotoxinas termoestáveis, atingindo o consumidor mesmo após o processo de pasteurização (GARCÍA et al., 2014; BARRETO et al., 2012; FAGUNDES et al., 2010).

Desta forma, o consumo de leite sem tratamento prévio como a pasteurização, expõe a população a diversas doenças como a tuberculose e a brucelose, entre outras, além de não assegurar a distribuição de um produto inócuo para consumo, para tanto, para ser considerado um leite de qualidade, o mesmo precisa apresentar qualidade sensorial, nutricional e físico-química, bem como contagem reduzida de células somáticas e baixa carga microbiana (SCABIN et al, 2012; SILVA et al, 2017).

\section{Conclusão}

Com o presente estudo pode-se concluir que existe a presença de vários micro-organismos na cadeia produtiva do leite brasileiro, que são contaminantes do leite cru e causadores da mastite bovina. Os micro-organismos com maior ocorrência entre os estudos analisados foram Staphylococcus aureus, Streptococcus spp., Corynebacterium spp. e o Escherichia coli. Conclui-se também, que os controles e protocolos estabelecidos para garantia da qualidade do leite, são ferramentas importantes na detecção da presença de microorganismos no leite, e devem ser aplicados visando sempre boas práticas de higiene durante a produção, processamento e armazenamento do leite, e consequentemente a produção de produto de elevada qualidade.

\section{Referências}

ACOSTA, A.C. et al. Mastites em ruminantes no Brasil. Pesq. Vet. Bras., v.36, n.7, p.565- 573, 2016. doi: 10.1590/S0100736X2016000700001

ÂNGELO, F.F.; BARBOSA, A.O.; ARAÚJO, A.O. Staphylococcus coagulase positivo isolado de leite cru de Tanques comunitários. Rev Cient. Med. Vet., v.12, n. 22, 2014.

BARRETO, N. et al. Qualidade microbiológica e suscetibilidade antimicrobiana do leite in natura comercializado em Cruz das Almas, Bahia. Semina: Ciênc. Agrárias, v.33, n.6, p.2315-2326, 2012.

BETTANIN, J. et al. Frequência de Isolamentos dos Agentes Etiológicos da Mastite Bovina no Sudoeste Paranaense. Rev Bras. Higiene Sanidade Anim., v.13, n.4, p.440-451, 2019.

BRASIL. 2011. Ministério da Agricultura, Pecuária e Abastecimento. Instrução Normativa 62. Diário Oficial da União. Brasília: MAPA, 2011.

Brasil. 2015. Ministério da Agricultura, Pecuária e Abastecimento. Portaria No 265, De 26 De Dezembro De 2015. Diário Oficial da União. Publicado em: 21/12/2015 | Edição: 230 | Seção: 1 | Página: 37-38.

Brasil. 2017. Presidência da República. Decreto No 9,013, De 29 De março De 2017. Diário Oficial da União. http://www.planalto. gov.br/ccivil_03/_ato2015-2018/2017/decreto/d9013.htm

Brasil. 2018a. Ministério da Agricultura, Pecuária e Abastecimento. Instrução Normativa $N^{\circ} 76$, De 26 De Novembro De 2018. Diário Oficial da União. Publicado em: 30/11/2018 | Edição: 230 | Seção: 1 | Página: 9.

Brasil. 2018b. Ministério da Agricultura, Pecuária e Abastecimento. Instrução Normativa $N^{\circ} 77$, De 26 De Novembro De 2018. Diário Oficial da União. Publicado em: 30/11/2018 | Edição: 230 | Seção: 1 | Página: 10.

BRASIL. 2019. Empresa Brasileira de Pesquisa Agropecuária EMBRAPA. Ministério da Agricultura, Pecuária e Abastecimento. Anuário do leite, p.104, 2019.

BRITO, D. A. P. et al. Prevalência e etiologia da mastite em bovinos leiteiros da Ilha de São Luís, estado do Maranhão, Brasil. Rev. Bras. Med. Vet., v. 36, n. 4, p. 389-395, 2014. 
CASTrO, B. G.; SOUZA, M. M. S.; BITTENCOURT, A. J. Prevalência e etiologia da mastite subclínica na região sul fluminense. Rev. Acad., Ciênc. Agrár. Ambient., v.10, n.3, p.263268, 2012. doi:10.7213/academica. 7710

CEMPÍRKOVÁ, R.; MIKULOVÁ, M. Incidence of psychrotrophic lipolytic bacteria in cow's raw milk. J. Anim. Scie. v. 54, p.65-73, 2009.

COSTA, G. M. et al. Resistência a antimicrobianas em Staphylococcus aureus isolados de mastite em bovinos leiteiros de Minas Gerais, Brasil. Arq. Inst. Biol., v.80, n.3, p. 297-302, 2013.

CUNHA, A. F. et al.; Prevalência, etiologia e fatores de risco de mastite em rebanhos leiteiros de Viçosa-MG. Acta Vet. Bras., v.9, n.2, p.160-166, 2015.

FAGUNDES, H. et al. Ocorrência de Staphylococcus aureus em leite cru produzido em fazendas leiteiras no estado de São Paulo, Brasil. Braz. J. Microbiol., v. 41, n. 2, p. 376-380, 2010. doi: 10.1590/S1517-83822010000200018.

FIORAVANTI, C. 2019 foi o ano mais quente já registrado no Brasil - Temperaturas máxima e mínima anuais sobem de modo contínuo desde 1961. Revista Pesquisa Fapesp, online. Disponível em: https://revistapesquisa.fapesp.br/2019-foi-oano-mais-quente-ja-registrado-no-brasil/\#: : text $=\mathrm{O} \% 20 \mathrm{ano} \% 20$ de $\% 202019 \% 20$ foi,Mapa) $\% 2 \mathrm{C} \% 20$ que $\% 20$ acompanha $\% 20$ a\%20varia\%C3\%A7\%C3\%A3o. Acesso em: 17 mar. 2020.

GARCÍA, M. E. T. A.; COUTO, E. P.; FERREIRA, M. A. Leite orgânico produzido no distrito federal: avaliação da qualidade físico-química e microbiológica. $A S A$, v.2, n.3, 2014.

JARDIM, J. G. et al. Perfil etiológico da mastite bovina na bacia leiteira do oeste paranaense, Paraná, Brasil. Rev. Bras. Med. Vet., v. 36, n.1, p. 65-70, 2014.

LANGONI, H. et al. Aspectos microbiológicos e de qualidade do leite bovino. Pesq. Vet. Bras. v. 31, n. 12, p. 1059-1065, 2011. doi: 10.1590/S0100-736X2011001200004.

MARTINS, R. et al. Prevalência e etiologia infecciosa da mastite bovina na microrregião de Cuiabá-MT. Ciênc. Anim. Bras., v.11, n.1, p.181-187, 2010. doi: 10.5216/cab.v11i1.5085.

MASSOTE, V. P. et al. Diagnóstico e controle de mastite bovina: uma revisão de literatura. Rev. Agrovet. Sul de Minas, v. 1, n. 1, p. 1-14, 2019.

MATTOS, M. R. et al. Qualidade do leite cru produzido na região do agreste de Pernambuco, Brasil. Semina: Ciênc. Agrárias, v. 31, n. 1, p. 173-182, 2010.

MONARDES, H. Reflexões sobre a qualidade do leite. In: DÜRR, J.W. et al. O compromisso com a qualidade do leite no Brasil. 1. Passo Fundo: UPF, 2004.

MOON, J. S. et al. Antibiogram and Coagulase Diversity in Staphylococcal Enterotoxin- Producing Staphylococcus aureus from Bovine Mastitis. J. Dairy Sci., v.90, p.1716-1724, 2007. doi:10.3168/jds.2006-512.

MUMIC, B.; AGUIAR, K. A. P.; LIVRAMENTO, D. E. A importância do associativismo na organização de produtores rurais. Rev. Inic. Cient. LIBERTAS, v.5, n.1, p.5-22, 2015.

OLIVEIRA, A. A.et al. Monitoramento microbiológico da mastite bovina em rebanho holandês na região dos Tabuleiros Costeiros do estado de Sergipe, Brasil. Rev. Bras. Med. Vet., v.32, n.4, p.193-197, 2010.

PICOLI, T.; et al. Manuseio de ordenha como fator de risco na ocorrência de microorganismos em leite cru. Semina: Ciênc. Agrárias, v.35, n.4, p.2471-2480, 2014. doi: 10.5433/1679-0359.2014v35n4Suplp2471.

RIBEIRO, W. O. et al. Enumeração de micro-organismos causadores da mastite bovina e estudo da ação de antimicrobianos. Rev. Inst. Latic. Cândido Tostes, v.69, n. , p.4552, 2014. doi: 10.14295/2238-6416.v69i1.305.

RIBEIRO, L. F. et al. Escherichia colidiarreiogênica em leite cru, água e fezes bovinas de propriedades leiteiras não tecnificadas. Ciênc. Anim. Bras., v. 20, p. 47449, 2019. doi: 10.1590/10896891v20e-47449.

RUIZ, A. K. et al. Prevalência de mastite bovina subclínica e microorganismos associados: comparação entre ordenha manual e mecânica, em Pernambuco, Brasil. Rev. Health Anim., v. 33, n. 1, p. 57-64, 2011.

SAAB, A. et al. Prevalência e etiologia da mastite bovina na região de Nova Tebas, Paraná. Semina: Ciênc. Agrár., v.35, n.2, p.835-844, 2014. doi: 10.5433/1679-0359.2014v35n2p535.

SANTOS, M.V.; FONSECA, L.F. Estratégias para controle de mastite e melhorias da qualidade do leite. Pirassununga: Manole, 2007.

SANTOS, L. L.; PEDROSO, T. F. F. GUIRRO, E. Perfil etiológico da mastite bovina na bacia leiteira de Santa Izabel do Oeste, Paraná. Cie. Anim. Bras., Goiânia, v. 11, n. 4, p. 860-866, 2010. doi: 10.5216/cab.v11i4.3654.

SCABIN, K. E. M.; KOZUSNY-ANDREANI, D. I.; FRIAS, D. F. R. Qualidade microbiológica do leite in natura durante o processo de obtenção e após o resfriamento. Revista CES Medicina Veterinaria y Zootecnia, v. 7, n. 1, p. 11-21, 2012.

SENHORELLO, I.L.S. et al. Prevalência, etiologia, sensibilidade microbiana e fatores de risco associados à mastite no rebanho leiteiro bovino do Município de Alegre, Espírito Santo, Brasil. PUBVET, Londrina, v. 7, n. 22, p. 1619, 2013.

SGARBIERI, V.C. Revisão: Propriedades Estruturais e Físicas Químicas das Proteínas do Leite. Brazilian Journal of Food Technology, v. 8, p.43-56, 2005.

SILVA, A. C.; SILVA, F. F.; BETT, V. A prevalência de mastites em vacas leiteiras do município de Carlinda (MT), no ano de 2016. PUBVET, v.11, n.8, p.761-766, 2017. doi: 10.22256/ PUBVET.V11N8.761-766.

STAMFOD, T. L. M. et al. Enterotoxigenicidade de Staphylococcus spp. isolados de leite in natura. Ciênc. Tecnol. Aliment., v.26, n.1, p.41-45, 2006.

TEIXEIRA NETO, R. O. et al. Pasteurização de leite na própria embalagem em banho-maria. Ciênc. Tecnol. Aliment. v. 17, n. 2, p.142-147, 1997.

WALDNER L. C. et al. Field study of culling and mortality in beef cows from western Canada. Can. Vet. J., v. 50, p. 491-499, 2007.

ZANELA, M. B. et al. Análises de composição e estabilidade do leite ao álcool. In: Conferência internacional sobre leche inestable. Anais eletrônicos [...].Colonia: Instituto Nacional de Investigación Agropecuaria de Uruguay, 2011. 